\title{
Sandra Palhares ${ }^{1}$
}

\section{Operfil do professor de arte}

The art teacher profile

El perfil del profesor de arte 


\title{
Resumo
}

Partindo da própria biografia, enquanto docente de Educação Artística na formação de educadores, professores e nas Artes visuais, este artigo pretende analisar criticamente as transformações ocorridas, nas últimas 4 décadas, em Portugal, no ensino superior na área das Artes Visuais e no sistema artístico, com o objetivo de compreender os fatores e circunstâncias que impactam tanto no perfil do professor de Arte assim como no ensino das Artes.

A sucinta compilação relativa à oferta formativa no campo das Artes Visuais combinada com o cruzamento de dados disponibilizados por diferentes instituições, explana de forma rizomática, as interdependências entre a Educação Artística, os fenómenos artísticos e o sistema onde se insere, levando-nos a concluir que, de facto, estamos perante um novo paradigma no que diz respeito ao perfil do professor de arte.

Palavras-chave: Formação de professores. Artes Visuais. Educação Artística

\begin{abstract}
Starting from our biography, as an Artistic Education teacher in the training of educators, teachers and in the Visual Arts, this article aims to critically analyze the changes that have taken place, in the last 4 decades, in Portugal, in higher education in the area of Visual Arts and in the artistic system, with the objective of understanding the factors and circumstances that impact both the profile of the Art teacher and the teaching of Arts.

The succinct compilation on the training offer in the field of Visual Arts combined with the crossing of data provided by different institutions and the rhizomatic explanation about the interdependencies between Art Education, artistic phenomena and the system in which it operates, leads us to conclude that, in fact, we are facing a new paradigm with regard to the profile of the art teacher.
\end{abstract}

Keywords: Teacher training. Visual arts. Artistic education

1 Sandra Palhares é artista, professora e investigadora. Doutora Europeu em Belas Artes, Facultad de Bellas Artes de la Universidad del País Vasco. Orcid: https://orcid.org/0000-0003-4852-6290 email: sandrapalhares@ie.uminho.pt 


\section{Resumen}

Partiendo de la propia biografía, como docente de Educación Artística en la formación de educadores, docentes y en las Artes Visuales, este artículo tiene como objetivo analizar críticamente los cambios que se han producido, en las últimas 4 décadas, en Portugal, en la educación superior en en el área de Artes Visuales y en el sistema artístico, con el objetivo de comprender los factores y circunstancias que inciden tanto en el perfil del docente de Arte como en la enseñanza de las Artes.

La sucinta recopilación sobre la oferta formativa en el campo de las Artes Visuales combinada con el cruce de datos aportados por diferentes instituciones y la explicación rizomática sobre las interdependencias entre la Educación Artística, los fenómenos artísticos y el sistema en el que se desenvuelve, nos lleva a concluir que, de hecho, estamos ante un nuevo paradigma tanto en cuanto al perfil del profesor de arte.

Palabras clave: Formación de professores, Artes Visuales, Educação Artística. 
Partindo da própria biografia, enquanto docente da Educação Artística na formação de educadores, de professores e das Artes Visuais, este artigo pretende analisar criticamente as transformações ocorridas, nas últimas 4 décadas, em Portugal, no ensino superior em Belas Artes, com o propósito de refletir sobre os fatores e circunstâncias que impactam tanto no perfil do professor de Arte, como no ensino das Artes.

Uma vez que este artigo está integrado num dossiê sobre as diferentes problemáticas relacionadas com a formação de professores de Artes Visuais, reunindo textos de pesquisadores da Região Norte, Sul, Centro-Oeste, Sudeste e Nordeste do Brasil, da Argentina e uma de Portugal, importa apresentar uma breve síntese com contexto português, esperando que possa ser útil numa perspetiva macro da educação.

Portugal é um Estado da Europa Meridional, fundado em 1143, que ocupa uma área total de $92.212 \mathrm{Km} 2$ e cujo território continental se situa no extremo Sudoeste da Península Ibérica, fazendo fronteira com a Espanha e com o Oceano Atlântico, incluindo ainda duas regiões autónomas: os arquipélagos da Madeira e dos Açores, localizados no Oceano Atlântico. Em 2020, Portugal tinha 10298252 habitantes, sendo o quinto país mais envelhecido da União Europeia (INE, 2021).

Relativamente aos dados mais genéricos sobre a educação que importam referir para esta análise, são 396909 os alunos matriculados no ensino superior distribuídos por 34 Instituições Públicas e por 71 Estabelecimentos Privados (DEGE, 2021). A taxa de diplomados no ensino superior passou de 21,3\% em 2009 para 33,5\% em 2018 , sendo atualmente de $36,2 \%$, aproximando-se dos $40 \%$ da Meta -estratégia Europa 2020 . Neste aumento de $14,9 \%$, uma das áreas que mais cresceu no total dos diplomados foram as Artes: o número de diplomados por ano passou de 1500 para mais de 5000 mil (entre 1996/97 e 2016/17), sendo que as áreas em que se verificam mais inscritos são as áreas mais recentes do design e dos Media/Digital, ligadas à internet e indústrias criativas e não as Belas-Artes. Em 2016-2017, contabilizaram-se 5159 diplomados em Artes, colocando as Artes no 3 lugar da área de formação no total de diplomados (DGEEC, 2019). No sentido inverso, na área da Educação verificou-se um decréscimo do número de diplomados na ordem dos 30\% (DGEEC, 2019), ao invés da maioria dos países que integram a União Europeia.

Resta acrescentar que existe um envelhecimento progressivo dos docentes em todos os níveis de ensino, mais evidente no ensino universitário e ligeiramente mais acentuado no grupo etário dos 50 ou mais anos de idade (CNE, 2019).

Esta breve compilação introdutória pretende relacionar os números da educação com a dimensão do país, para que se tenham em consideração as distintas escalas e respetivas realidades relativas à Formação de Professores de Arte, nas diferentes regiões dos 3 países localizados em 2 continentes. 


\section{A oferta formativa em Artes Visuais no Ensino Superior}

Centremo-nos, agora, nas alterações nas últimas décadas em Portugal, inicialmente decorrentes das mudanças após a Revolução dos Cravos de 25 de Abril de 1974, no campo das Belas Artes e cuja designação tem vindo a ser, gradualmente, substituída por outras, mais contemporâneas, tais como, Artes Visuais ou Artes Plásticas.

No caso particular da instituição onde iniciei a formação inicial, a Escola Superior das Belas Artes do Porto, pioneira do ensino artístico em Portugal, a par da congénere em Lisboa, a ESBAL, a reforma foi reconhecida, posteriormente, pelo Decreto-lei $n . \circ 80 / 83$, de 9 de fevereiro.

Em 1986 é estabelecido o quadro geral do sistema educativo, como o referencial normativo das políticas educativas aprovado pela Lei de Bases do Sistema Educativo Português, sucessivamente alterada em 1997, 2005 e 2009.

Ainda nos anos 80, mais precisamente entre o fim desta década e o início da seguinte, inicia-se o processo de integração das Escolas Superiores de Belas Artes nas Universidades e, em 1992, a FBAUL E FBAUP mudam o estatuto de Escola Superior para o de Faculdade.

Um pouco mais tarde, já no final da década, em 1999, inicia-se o Processo de Bolonha, originando novas alterações ao nível da formação académica e subsequentes graus conducentes a títulos. Nesse sentido, a formação em Artes Visuais, e à semelhança das outras áreas do conhecimento, foi, numa 1ํ fase, sujeita a mudanças decorrentes da revolução e, mais tarde, foi sendo gradualmente integrada no processo de reforma intergovernamental a nível europeu, o Processo de Bolonha, com vista à concretização no Espaço Europeu de Ensino Superior e ao reconhecimento mútuo de graus, comparáveis e organizados numa estrutura de 3 ciclos.

A formação académica em Artes Visuais foi, assim, passando a estar assente no trabalho em atelier/ estúdio estruturado num contínuo conceptual com o objetivo de desenvolver competências práticas, técnicas, artísticas e teóricas relacionadas com as Artes, integrando-se no referido sistema europeu de graus baseado em 3 ciclos de estudo, adotando o sistema de créditos curriculares (ECTS) baseado no trabalho do estudante, oficializado em Portugal pelo Decreto-lei 74/2006 de 24 de março. Deste modo, também a formação do professor de Arte no campo de saberes e práticas que a designação "Belas-Artes" abrange, passou a estar integrada na mais recente organização do ensino europeu.

Desde o processo de Bolonha, a licenciatura (1ํㅜ ciclo) passou a ter uma duração menor do que a anterior, variável entre os 6 e os 8 semestres, dotando os alunos de conhecimentos básicos na área científica das Belas Artes e de competências instrumentais e sistémicas essenciais para a empregabilidade ou para o prosseguimento de estudos de nível superior, nomeadamente de mestrado ( $2^{\circ} \mathrm{ciclo}$ ).

Atualmente, em Portugal, os planos de estudos dos cursos de licenciatura em Artes Plásticas ou Artes Visuais, na sua grande maioria, proporcionam uma formação mais alargada e, em alguns dos cursos, estruturam-se a partir de práticas artísticas 
mais contemporâneas e tecnológicas, ao contrário do tradicional campo de saberes enraizado nos ramos específicos como a Pintura e a Escultura.

De facto, as alterações nos títulos conferentes de grau são representativas da evolução de um conjunto alargado de práticas artísticas contemporâneas mais tecnológicas, mais híbridas ou que tendem para uma maior desmaterialização da obra de Arte, ainda que a designação de Belas-Artes, cujo conceito incorporado no vocabulário da história de arte desde o século XVIII, se mantenha nas instituições de referência histórica, pese embora, nas mais recentes seja utilizado o conceito de Artes Visuais, Arte ou Arte Contemporânea, muito à semelhança do que sucede com alguns dos espaços museológicos e expositivos.

Considerando a especificidade epistemológica das Artes, a palavra "Arte" foi evoluindo para um conceito mais agregador de diferentes graus de especialidade, tornando-se uma espécie de catalisador da complexidade das relações inerentes à criação artística que convoca, estabelece, cruzando as Artes Visuais com outros campos do saber.

\section{Os cursos de Licenciatura em Portugal}

Existem 22 cursos de licenciatura acreditados pela Agência de Avaliação e Acreditação do Ensino Superior (A3ES) em funcionamento nas universidades e demais instituições de ensino superior portuguesas, em 2021, que passaremos a elencar, em seguida:

1. FBAUL - 2 Licenciaturas: em Pintura e em Escultura;

2. FBAUP - Licenciatura em Artes Plásticas;

3. ESAD, IPL - Licenciatura em Artes Plásticas;

4. U Lusófona - Licenciatura em Artes Plásticas;

5. FCHS - UA, Licenciatura em Artes Visuais;

6. Cesap - Licenciatura em Artes Plásticas e Intermédia;

7. ESE, IPVC - Licenciatura em Artes Plásticas e Tecnologias Artísticas;

8. EST, IPT - Licenciatura em Artes Plásticas - Pintura e Intermédia;

9. ESE, IPV - Licenciatura em Artes Plásticas e Multimédia;

10. EA, UM - Licenciatura em Artes Visuais;

11. EA, UE - Licenciatura em Artes Visuais - Multimédia;

12. ESE, IPP - Licenciatura em Artes Visuais e Tecnologias Artísticas;

13. FAH, UM - Licenciatura em Artes Visuais;

14. Cesap - Licenciatura em Artes Visuais - Fotografia;

15. ESE, IPL - Licenciatura em Artes Visuais e Tecnologias;

16. ESAG, Cesap - 2 Licenciaturas: em Artes/BD/Ilustração e em Artes/ Grafismo Multimédia;

17. U Maia - Licenciatura em Artes e Multimédia; 
18. ESAD - Licenciatura em Artes Digitais e Multimédia;

19. ESG - Licenciatura em Multimédia e Artes;

20. ESSE, IPB, Licenciatura em Arte e Design.

Para além do conjunto das 23 licenciaturas habilitarem para a criação artística, vulgo artista visual ou plástico, pintor, escultor, os licenciados podem optar por outras saídas profissionais, consideradas ramos afins que vão desde a animação, os audiovisuais, a fotografia e os media digitais, meios e redes de comunicação social, ateliers de design, agências e departamentos de marketing e publicidade, integrar equipas de ilustração, de cinema, o teatro, a dança, as artes performativas, a música e o som de criação artística e cultural. Nesse sentido, uma grande parte da oferta da formação inicial do 1은 ciclo e, apesar das diferenças entre nomenclaturas e respetivos planos de estudo, visa proporcionar ao aluno a aquisição de um conjunto mais alargado de competências, tornando-o mais qualificado e competitivo para a inserção no mercado de trabalho com a ambição de conferir capacidades e acesso a postos de trabalho qualificados em diferentes âmbitos de atividade profissional relacionada com as Artes, a criação, a programação e consultoria artística, as Ciências da Arte e a consequente investigação.

\section{Os cursos de Mestrado em Portugal}

Os cursos de Mestrado, no $2^{\circ}$ ciclo de estudos, têm uma duração entre 3 e 4 semestres, requerendo a frequência de unidades curriculares, a elaboração de uma tese original, a defender em provas públicas, ou a realização de um estágio em contexto profissional e a elaboração e defesa do respetivo relatório, no caso dos mestrados profissionalizantes.

Elencamos, de seguida, a oferta educativa ao nível do 2 ํ Ciclo:

1. FBAUL - Cursos de Mestrado em:
a. Arte e ciência do vidro e da cerâmica;
b. Arte multimédia;
c. Ciências da conservação, restauro e produção de arte contemporânea;
d. Crítica, curadoria e teorias da arte;
e. Desenho;
f. Design de interação;
g. Design para a sustentabilidade;
h. Educação artística;
i. Ensino de artes visuais;
j. Escultura;
k. Museologia e museografia;
l. Pintura
m. Práticas tipográficas e editoriais contemporânea; 
2. FBAUP - Cursos de Mestrado em:

a. Arte e Design para o Espaço Público Web;

b. Design da Imagem Web;

c. Design Gráfico e Projetos Editoriais;

d. Design Industrial e de Produto (Curso conjunto com FEUP);

e. Estudos de Arte Web;

f. Mestrado em Artes Plásticas;

g. Mestrado em Ensino de Artes Visuais no 3‥ Ciclo do Ensino Básico e no Ensino Secundário (Curso conjunto com FPCEUP);

h. Mestrado em Multimédia (Curso conjunto com FEUP, FCUP, FEP, FLUP);

3. EA, UE - Mestrado em Práticas Artísticas em Artes Visuais;

4. ESAP - Mestrado em Artes Visuais. Práticas Artísticas e Investigação;

5. ESAD, IPL - Mestrado em Artes Plásticas;

6. ESAD, IPL - Mestrado em Artes do Som e da Imagem;

7. ESE, IPP - Mestrado em Património, Artes e Turismo Cultural;

8. ESHTE - Mestrado em Inovação em Artes e Ciências Culinárias;

9. Universidade Lusófona de Humanidades e Tecnologia - Mestrado em Artes da Animação;

10. CA, UC - Mestrado em Estudos Curatoriais;

11. U Lusófona - Mestrado em Ensino de Artes Visuais no 3․ Ciclo do Ensino Básico e no Ensino Secundário.

Segundo o atual regime jurídico da habilitação profissional para a docência na educação pré-escolar e nos ensinos básico e secundário, a habilitação para a docência passou a ser exclusivamente profissional, deixando de existir a habilitação própria (cursos científicos anteriores ao Processo de Bolonha que constam de diverso normativos publicados entre 1984-2007), pelo que a partir de 2007, os Mestrados em ensino passaram a ser os cursos que habilitam e qualificam para a docência (Decreto-Lei n.ำ 79/2014).

\section{Os cursos de Doutoramento em Portugal}

O 3ำ ciclo, no campo das Artes Visuais, mais precisamente, os cursos de doutoramento, implicam a elaboração e defesa pública de uma tese, ainda que os critérios da investigação possam ser mais ou menos variáveis, dependendo da instituição de ensino superior, e desde que cientificamente seja um contributo considerável para o conhecimento da área das Artes Visuais.

Os planos de estudos de 3 ำ ciclo variam consoante as instituições onde estão alocados. No entanto, estruturam-se maioritariamente com base numa grande área científica das artes plásticas que, em alguns dos casos, se divide depois em áreas 
científicas de especialização que capacitam para a conceção e produção de obras nos domínios da visualidade em suportes bidimensional, tridimensional e digital, bem como conteúdos multimédia e audiovisuais.

Apesar das diferenças, todos habilitam para o exercício de atividades relacionadas com o ensino e com o mercado de arte e do design. Para além de capacitar para áreas profissionais interdisciplinares que envolvem a realização de projetos de criação, teoria, gestão artística, mediação cultural, design contemporâneo e, outras especialidades do campo das artes visuais e media arte, os cursos de 30 ciclo capacitam para a investigação artística e/ ou científica nas áreas similares às variantes, integrando o sistema de atividades relacionadas com a literatura, crítica de arte, curadoria e campos afins.

Neste sentido, são também frequentes as diferenças entre as terminologias e respetivas estruturas curriculares dos cursos de Doutoramento que encontramos nas diferentes universidades portuguesas que conferem o grau de Doutor nesta área científica:

1. IE, UM - Doutor em Estudos da Criança, Especialidade de Educação Artística (Educação Visual);

2. FBAUL - Doutor em:

a. Pintura;

b. Escultura;

c. Desenho;

d. Arte Multimédia;

e. Ciências da Arte e do Património;

f. Design de Comunicação;

g. Design de Equipamento;

3. FBAUP - Doutor em:

a. Artes Plásticas Web;

b. Educação Artística Web, Curso conjunto com DESC, FPCEUP, DESC;

c. Media Digitais, Curso conjunto com: FEUP, FCUP, FEP, FLUP, UNL

4. $\quad \mathrm{CA}, \mathrm{UC}$ - Doutor em Arte Contemporânea Colégio das Artes;

5. EA, UCP - Doutor nas Ciências e Tecnologias das Artes;

6. U Lusófona - Doutor em Arte dos Media.

\section{Uma breve reflexão sobre a oferta educativa na formação de professores de Arte}

Esta sucinta inventariação relativa à oferta formativa no âmbito da formação em Artes Visuais, nos 3 ciclos de estudo pós Processo de Bolonha, teve como objetivo escrutinar o estado da arte no ensino superior português na área das Artes Visuais. 
Pretendia-se, assim, analisar e compreender as respetivas variáveis que existem, atualmente, para refletir sobre a adequação da oferta educativa na formação de professores de Arte, segundo as atuais lógicas sistémicas do campo das Artes.

Como se pode depreender do conjunto de cursos listados e relativos ao $1 \stackrel{\circ}{\mathrm{ci}}$ clo de estudo, as titulações que complementam as Artes com outras terminologias, tais como Multimédia, Intermedia e Tecnologia, ambicionam uma formação de banda mais larga com vista a ampliar o espectro de competências e, por conseguinte, proporcionar uma maior adaptabilidade ao mercado de trabalho.

Relativamente ao $2^{\circ}$ ciclo, os cursos de mestrado seguem a lógica de especialização num determinado ramo, ao invés da lógica de espectro mais alargado do ciclo prévio. Esse leque é mais evidente em algumas das designações dos cursos de licenciatura listados, que visam proporcionar um conjunto de competências mais vasto, com vista ao alargamento das saídas profissionais.

No que diz respeito aos cursos de 3 ㅇ ciclo, convém referir que algumas estruturas curriculares se distinguem por uma investigação multidisciplinar dirigidas à criação artística, focada tanto nas questões autorais e conceptuais artísticas, quanto no seu desenvolvimento tecnológico e na sua relação com áreas científicas através de abordagens trans, multi e interdisciplinares, cruzando diferentes meios, técnicas, domínios.

Pese embora a natureza, mais ou menos trans, multi e interdisciplinares, relativas à oferta educativa do 3 을 ciclo listada, as ditas estruturas curriculares confluem, umas mais, outras menos, para a lógica de especialização de um 3ํㅜ ciclo de estudos. Desse modo, aspiram a uma espécie de equilíbrio entre a abrangência que estrutura a base de uma grande área científica das artes visuais e a natureza deste ciclo de estudos. Não obstante, as estruturas curriculares do 3ำ ciclo correspondem a um paradigma diverso da epistemologia da criação emergente e gerador de hibridismos mercê do alargamento da extensão dos objetos e campos de ação artísticos e que, em certa medida, tendem a contrariar a especialização disciplinar dos doutoramentos.

Resta acrescentar que desde que se iniciou o Processo de Bolonha também se iniciou um debate sobre a natureza dos estudos ao nível do 3ำ ciclo desta área do conhecimento. Nesse sentido, questiona-se se a natureza da investigação deve ser, à semelhança do que acontece nos outros domínios do saber, segundo a lógica e normas académicas, ou se se deve considerar a natureza da praxis artística, ou se, finalmente e em alternativa, se devem combinar ambas, como sucede com algumas estruturas curriculares de instituições congéneres anglo-saxónicas.

Independentemente dos diferentes ciclos de estudo e respetivas titulações dos cursos listados, no âmbito do ensino superior, as recentes designações per si, já são representativas de uma determinada evolução e ampliação do território estético. 


\section{A Educação Artística no Currículo em Portugal}

Chegados a este ponto, importa referir algumas atualizações relativas à Educação Artística no currículo português. Em 2016, a área de Expressão Visual e Plástica passa a ser designada por subdomínio das Artes Visuais nas OCEPE e em 2018, na continuidade, os programas das Aprendizagens Essenciais - Ensino Básico, 2ำ e 3은 ciclo, passa-se a utilizar o conceito de Artes Visuais em conformidade com o sucedido no Currículo Nacional Ensino Secundário, Oferta Formativa Cursos Científico-Humanísticos (OF).

De facto, comparando o Currículo Nacional do Ensino Básico - Competências Essenciais (2001) com a atualização das Aprendizagens Essenciais (2018) referentes ao Ensino Básico, podemos constatar uma evolução significativa. Alguns dos programas anteriores referiam-se às Artes como sendo um elemento indispensável ao desenvolvimento pessoal, social e cultural do aluno, enquanto que os atuais que integram o Currículo do Ensino Básico, referem as Artes Visuais como uma área do conhecimento fundamental para o desenvolvimento global e integrado dos alunos, em consonância com as diferentes Áreas de Competências do Perfil dos Alunos à Saída da Escolaridade Obrigatória.

A referência às últimas revisões curriculares transversais aos 12 anos de escolaridade obrigatória e que, sobejamente sabemos, alicerçam a formação pré-universitária, pretendeu, humildemente, vislumbrar uma espécie de concertação entre os diferentes níveis de ensino. Estas alterações são também um indicador da necessária atualização do saber de uma área do conhecimento que, historicamente, foi sempre valorizada enquanto legado da Humanidade, mas que, por outro lado, foi sempre relegada no âmbito da produção de conhecimento científico e académico.

Resta referir as lógicas complexas e sistêmicas inerentes à criação artística e às relações interdependentes com as novas dinâmicas que emergem da cultura contemporânea, nomeadamente, das novas indústrias culturais e da intensificação do consumo cultural no limiar da viragem do milénio.

Essas interdependências entre os fenómenos artísticos e o sistema onde se inserem extravasam as questões de produção e criação artística, marcando uma viragem na formação académica, a qual se vê obrigada a integrar as questões de comunicação, curadoria, mercado, etc., inerentes às complexas lógicas sistêmicas em volta da Arte Contemporânea, intimamente conectadas à globalização enquanto fluxo gerador de múltiplas formas de globalização cultural.

\section{O estado da Arte}

Lipovetsky tem vindo a argumentar que o conceito de cultura se alterou, designando de cultura-mundo o sistema económico-cultural do hipercapitalismo globalizado e a Arte também está integrada no sistema midiático e econômico (LIPOVETSKY; SERROY, 2018). Boris Groys (2014) também assevera que, desde finais do 
século XX, a Arte entrou numa nova era: a da produção artística massiva. De facto, não se pode, hoje, falar da Arte sem considerar a dita interdependência, mesmo que persista inalterável a compulsão sempiterna para a criação artística ao longo da História da Humanidade.

Vivemos num tempo hipermoderno, na "cultura-mundo" de que nos fala Lipovetsky (LIPOVETSKY; SERROY, 2018, p.15) e que, segundo o filósofo, nos remete para a realidade planetária hipermoderna, onde, pela primeira vez, a economia do mundo se organiza segundo um modelo único de normas, de valores e objetivos - o ethos e o sistema tecnocapitalista - e onde a cultura se impõe como mundo econômico de pleno direito. Lipovetsky vem desenvolvendo a ideia de que o mercado integra cada vez mais, na sua oferta, as dimensões estética e criativa do imaginário cultural que se vai difratando pelo mundo material, sendo uma das razões que evoca para explicar porque é que a cultura-mundo cobre um território mais vasto do que o da "cultura" culta, cara ao humanismo.

E se ao longo da humanidade, como referimos antes, a Arte foi sendo sempre uma espécie de compulsão maior para materializar o mundo sensível através da imagem ou da forma, hoje assistimos a um outro tipo de compulsão massiva: (quase) todos podemos produzir imagens e, cada vez mais, comunicamos através de imagens em detrimento da palavra.

De facto, vivemos na era da híper-abundância de imagens. Grande parte das imagens são hoje produzidas pelo Homo photographicus. Segundo Fontcuberta, a genealogia do Homo photographicus inicia-se com a pintura rupestre, prossegue com os artistas pintores, os fotógrafos profissionais e, finalmente, com os foto-aficionados (FONTCUBERTA, 2016, p.117) que, muito provavelmente, estão mais "interessados em produzir imagens do que em vê-las" (GROYS, 2014, p.14).

É nesta encruzilhada que se encontra a criação artística, ainda que as Artes engendrem sempre uma outra vontade, a do fazer e agir para além das lógicas do tempo hipermoderno, híper tecnificado!

Na continuação de analisar as lógicas sistémicas, vamos refletir sobre o impacto do desenvolvimento dos museus e centros de exposição.

No último quartel do milénio, mais precisamente, nos anos 80 e com a intensificação da globalização, dá-se um boom museológico sem precedentes. Mas o que importa para esta análise o status quo dos museus? Importa, no sentido de nos ajudar a compreender a origem de um maior interesse pela Arte, independentemente, de hipotéticos efeitos colaterais suscitados por alguma crítica relativa aos efeitos 'blockbusters' de determinadas exposições de Arte, mais focadas no entretenimento do que na educação.

De facto, estas dinâmicas geradas por uma nova conceção do espaço museológico, intimamente ligado à indústria e ao turismo cultural tiveram e, continuam a ter, um forte impacto nas práticas artísticas contemporâneas.

Uma grande parte dos museus criados nas últimas décadas foram projetados por "starchitects", célebres por uma arquitetura disruptiva, por vezes marcadamente 
escultórica que, em alguns casos, projetavam obras 'faraónicas' devido sobretudo à envergadura construtiva, ao desenho ou aos materiais e/ou técnicas inovadoras, gerando ainda mais atenção.

Como bem profetizou Debord (2012, p. 47), "o espetáculo é o capital a um tal grau de acumulação que se torna imagem".

E não há dúvida que as imagens arquitetónicas dos 'starchitects' cabem nesta profecia.

Exemplo deste paradigma é o Museu Guggenheim, em Bilbao, Espanha. Passados 24 anos desde a sua inauguração, ainda se fala do 'efeito Guggenheim '. A criação do museu contribuiu para a reabilitação de uma economia industrial deteriorada e enfraquecida pela globalização, impulsionando a cultura como alavanca do desenvolvimento económico da cidade, colocando-a nos roteiros do turismo cultural global.

Desde os finais do século $X X$, à semelhança do fenómeno do Guggenheim basco, e a par das dinâmicas do turismo cultural, foram surgindo novos museus localizados em distintas geografias globais e, num ápice, as imagens destes museus popularizaram-se através da incessante hiper circulação e mediação que caracteriza a cultura visual do mundo globalizado. Alguns destes museus converteram-se em símbolos de destinos turísticos alinhados com o hiperconsumo, uniformizado pelos canais de informação, gerando uma espécie de 'electronic common sensé (KERCKHOVE, 1997), ou seja, proporcionando noções de tempo, espaço e sociedade comuns devido à virtualização cada vez maior dos valores e de referências físicas, numa linguagem cada vez mais visual e trans linguística, comunicando de golpe e de forma global e, tal como previa Débord (2012, p. 23), "onde a realidade se transforma em simples imagens, as simples imagens transformam-se em realidade".

Melot (2014) advertiu que a natureza da imagem é da relação. E não há dúvida que a relação da imagem é dependente das relações de determinado contexto histórico, corroborando a ideia Canclini (1979, p.42) quando afirma de que toda a Arte está condicionada socialmente, ainda que nem toda a arte seja definida socialmente.

É precisamente a partir destas perspetivas que pretendemos compreender de que forma as circunstâncias descritas favoreceram e impulsionaram um maior desenvolvimento das Artes Visuais nas últimas décadas e quais são as repercussões na formação do professor de Arte.

Neste sentido, o desenvolvimento da criação artística alimenta o circuito dos museus integrados nos itinerários do turismo cultural, promovidos por políticas culturais, na sua grande maioria financiadas por capitais corporativos ou filantrópicos, gerando atividade a diversos profissionais, desde curadores, consultores, galeristas, leiloeiras, marchands, etc.

Estas circunstâncias, inevitavelmente, têm desencadeado muitos debates, desde a dificuldade em distinguir a prática da ação museológica das práticas das indústrias da cultura, do entretenimento e do turismo, até às polémicas relativas à especulação do mercado da Arte. 
Contudo e, mesmo que se possa reconhecer a componente lúdica nas práticas museológicas, a par da pressão turística, os museus não estão totalmente reféns do turismo ou do entretenimento e, sem dúvida, no caso particular português têm sido alavancas para a produção artística, contribuindo, inegavelmente, para uma maior atenção pelas Artes.

Esta explanação à volta da evolução dos museus e das dinâmicas entre a indústria cultural e o turismo, pretende explicitar as interdependências referidas antes e, ainda, evidenciar a necessidade de integrar o conhecimento sobre os mecanismos de funcionamento artístico no ensino, precisamente, porque a oferta formativa académica visa capacitar e integrar os profissionais no sistema artístico.

Focando no contexto português, convém referir que, após a Revolução do 25 de abril de 1974, surgiu um número considerável de equipamentos culturais, maioritariamente, nas últimas décadas, acompanhando o referido 'boom' museológico. Este facto contribuiu para alicerçar o desenvolvimento da nova indústria cultural, tanto ao nível do desenvolvimento da produção cultural e artística, como ao nível da criação de públicos. Apesar do reconhecimento deste incremento cultural, o investimento político português na cultura continua aquém do desejável e recomendável.

A criação de equipamentos culturais, em Portugal, colmatam algumas lacunas e são também uma reação à estagnação cultural causada pelo Estado Novo.

Até à pandemia, alguns destes equipamentos culturais eram também ativos contribuintes para a economia portuguesa no contexto europeu que, estrategicamente, delineou a viragem de uma economia produtiva assente no setor industrial e agrícola para uma economia fortemente baseada nos serviços, apostando na cultura como alavanca para o negócio, considerando-a um ativo diferenciador e competitivo.

Portanto, até à era pré-Covid, a economia portuguesa convergia para o setor turístico, alicerçado em ativos diferenciadores e competitivos, tais como a identidade e tradição lusa e, finalmente, a cultura, num sentido muito lato e onde se inclui a Arte.

Já em 2008, na feira de Turismo de Madrid, Portugal, estrategicamente, fazia da cultura bandeira, promovendo museus de arte e outros equipamentos culturais projetados por arquitetos famosos, associando à campanha artistas visuais mediáticos como é o caso da artista plástica, Joana Vasconcelos, a par de grandes figuras populares do fado e do futebol.

Para que se tenha uma ideia do fenómeno turístico cultural em Portugal, em 2019 registaram-se 19777691 visitantes a museus, sendo que 6009392 correspondem aos museus de Arte (INE, 2020), gerando um impressionante impacto económico num país com 10298252 habitantes.

Chegados a este ponto, importa mencionar os 3 museus e centros de exposição que estão na génese da mudança do paradigma da Arte Portuguesa e que são, de algum modo, representativos das dinâmicas descritas acima, ajudando-nos a compreender as repercussões no sistema artístico, na oferta formativa e na subsequente formação do professor de Arte. 
Seguindo uma lógica cronológica, começamos por referir o Centro de Arte Moderna Azeredo Perdigão da Fundação Calouste Gulbenkian, inaugurado em 1983, 0 Centro Cultural de Belém, inaugurado uma década mais tarde, em 1993, ambos em Lisboa e, finalmente, o Museu de Arte Contemporânea de Serralves, inaugurado em 1999, localizado na segunda maior cidade do de Portugal, o Porto. Estes 3 equipamentos culturais marcaram profundamente o panorama artístico em Portugal, mantendo até aos nossos dias uma intensa atividade no que diz respeito à criação e divulgação das Artes. As 3 instituições são ainda pioneirs na oferta educativa artística não formal.

No caso particular de Serralves e, na qualidade de docente utilizador do serviço pedagógico, reconheço a eficácia da estratégica de marketing relativamente à promoção do acesso democrático ao museu e respetivos serviços pedagógicos, seja através das escolas ou através da organização de grandes eventos de sucesso, como é o caso de "Serralves em Festa".

À semelhança das dinâmicas geradas pelos 3 museus localizados nas 2 maiores cidades do país, Lisboa e Porto, nos últimos anos, foram surgindo em diferentes localidades do território português, outros equipamentos culturais .

Esta referência aos Museus e espaços expositivos mais recentes e dedicados à Arte Contemporânea, está circunscrita à região norte litoral portuguesa, localizando-se sobretudo em cidades com um forte legado industrial: Centro de Arte Oliva, em São João da Madeira; Centro Cultural Vila Flor e Centro Internacional de Arte José de Guimarães, ambos na cidade-berço de Guimarães; Casa das Artes, em Vila nova de Famalicão, ou, ainda, nos locais da naturalidade de alguns dos artistas nacionais (Museu de Arte Contemporânea Nadir Afonso, em Chaves; Centro de Arte Internacional José de Guimarães, Centro de Arte Contemporânea Graça Morais, em Bragança), etc.

Nas últimas décadas, o emparceiramento entre a escola e o museu foi acontecendo e os 3 museus localizados nas 2 grandes cidades têm vindo a afirmar-se como um fenómeno educativo distinto da escola através dos serviços pedagógicos, gerando sinergias que, muito provavelmente, contribuem para um processo de aprendizagem mais adequado a determinados fenómenos culturais contemporâneos. Todavia, estas experiências pedagógicas acentuam as assimetrias entre o litoral densamente povoado e a interioridade despovoada, evidenciando as limitações e dificuldades. Perante este cenário, é absolutamente necessário apostar na promoção do acesso à cultura e considerar uma maior representatividade da Educação Artística no Currículo, de forma a minimizar as desigualdades e as assimetrias identificadas no território português com vista à equidade cultural e educacional que alicerçam o "elevador social', tão referido no atual discurso político. 


\section{Conclusões}

Por tanto, a formação do professor de Arte assenta na narrativa tecnocrata de matriz europeísta, regendo-se por normas e regras que pretendem a mudança de paradigma de ensino no EEES (Espaço Europeu de Ensino Superior). Essa mudança visa a viragem do modelo baseado na transmissão de conhecimentos para um modelo baseado no desenvolvimento e aquisição de competências, onde se incluem, quer as de natureza genérica - interpessoais, instrumentais e genéricas -, quer as de natureza específica, relativas à área de formação, e onde a componente experimental e de projeto desempenham um papel importante. Portanto, a vertente mais experimental e projetual inerente ao ensino da Arte está hoje circunscrita a um conjunto de regulamentos e procedimentos legitimados por uma academia hegemónica, contrariando, em certa medida, a inquietude que caracteriza a criação artística.

Enfim, esta é uma possível visão da formação acadêmica atual em Portugal, tão tecnocrata quanto idílica, ou seja, a legitimação dos saberes que resultam da investigação artística integrada no conhecimento gerado pela academia.

Segundo Lipovetsky (2003), os artistas já não são identificados como costumavam ser: indivíduos à margem, de uma boémia social, representados simbolicamente por imagens que faziam deles seres à parte, profetas inspirados ou artistas malditos. Segundo o filósofo, existe hoje a profissionalização e especialização das atividades artísticas.

Chegados a este ponto, cabe perguntar: pode o professor de Arte ser produtivo em todas as dimensões que lhe são exigidas, nomeadamente, a docente, a artística e a investigativa de natureza científico-académica? As circunstâncias atuais parecem promover um professor assente num perfil Multitask ou Professor de Banda Larga.

Multitasking, coaching, mindfullness, etc., são inúmeros os termos anglo-saxônicos usados para descrever algum tipo de ações que, supostamente, ajudam a suportar um intenso e perverso engajamento com o trabalho, onde naturalmente, estão incluídas as Artes Visuais, outrora bem mais livres e marginais às normas e convenções.

De fato, o campo disciplinar das Artes Visuais expandiu-se e complexificou-se com a integração nas universidades, com o avanço tecnológico e respetivas repercussões nos modos de produção dos artefactos e das imagens e, finalmente, com o desenvolvimento da indústria cultural. As práticas e procedimentos artísticos, outrora bem mais específicos, hoje oscilam entre os modos de produção ancestrais e os novos interfaces visuais, enturvando fronteiras entre ramos específicos mais tradicionais no campo das Belas-Artes, outrora muito delimitados, tais como a pintura e a escultura, muito focados no "saber fazer" e, tradicionalmente, conotadas com o virtuosismo técnico.

Esta amplitude estética sem precedentes implica uma atualização contínua do docente, independentemente da especificidade da sua prática artística e respetivos interesses de investigação.

A temática do artigo é-me cara. Sou docente na área da Educação Artística, na especialidade de Educação Visual na formação de professores e, a tempo parcial, na 
área das Artes Visuais. Tem sido um privilégio lecionar em ambas as áreas, independentemente das respectivas especificidades, pelo facto de constatar que se nutrem reciprocamente. No entanto, enquanto professora/artista/investigadora acadêmica integrada na geração cuja formação académica decorreu, precisamente, entre a viragem do milénio e, por conseguinte, vivenciando as circunstâncias e as dinâmicas descritas, manifesto, aqui e agora, em modo de discurso direto, a necessidade urgente de uma maior adequação das normas e regras académicas, que validam e legitimam a formação docente no campo das Artes Visuais, às idiossincrasias da criação artística.

Mediante o panorama descrito, o professor de Arte está "ensaiando" uma espécie de "customização da educação artística", flexibilizando os conteúdos de acordo com os diferentes interesses dos alunos, ou pelo menos foi assim que, tentando manter alguma distância crítica, autoanalisei a minha prática pedagógica.

A pandemia originou profundas alterações na forma como vivemos e tivemos que nos adaptar a uma outra forma de ensinar Arte... Ainda hoje procuro alternativas para fruir e consumir cultura num tempo de uma aceleração digital sem precedentes. Nas universidades já se debate a alternativa de modelos mistos de aprendizagem, combinando a modalidade presencial com a digital.

Termino com a pergunta: qual será o perfil do professor de Artes para este novo paradigma? 


\section{Referências bibliográficas}

DEBORD, G. A Sociedade do Espetáculo. Lisboa: Antígona, 2012.

FONTCUBERTA, J. La Furia de las imágenes. Notas sobre a postfotografía, Barcelona: Galaxia Gutenberg. 2016.

KERCKHOVE, D. D. A Pele da Cultura. Uma Investigação sobre a Nova Realidade Eletrónica. Lisboa: Relógio d’Água Editores, 1997.

CANCLINI, N. G. La producción simbolica. Teoria y metodo en sociologia del arte. Buenos Aires: Siglo XXI. 1979.

GROYS, B. Volverse público: las transformaciones del arte en el ágora contemporánea. Buenos Aires/Madrid: Editorial Caja negra, 2014.

LIPOVETSKY, G.; SERROY, J. O Capitalismo Estético na Era da Globalização. Lisboa: Edições 70, 2014.

LIPOVETSKY, Gilles. A cultura-mundo. Lisboa: Edições 70, 2018.

MELOT, Michel, Uma breve história...da imagem, V. N. Famalicão:

Edições Húmus, 2015. 


\section{Referências sitiográficas}

A3ES (2021) Acesso em: maio 2021.

CNE (2019). Relatório Técnico: Acesso ao ensino superior, Disponível em: https:// www.cnedu.pt/content/noticias/CNE/RelatorioTecnico_Acesso_ensino_superior. pdf. Acesso em: maio 2021.

CNE (2020). Pareceres e Recomendações 2020 Disponível em:https://www. cnedu.pt/content/edicoes/pareceres_e_recomendacoes/Pareceres_e_ Recomendacoes-2020.pdf. Acesso em: maio 2021.

DGEEC (2019a). Prosseguimento de estudos entre os diplomados de Cursos de Técnico Superior Profissional. Lisboa: Autor. Disponível em: https://www.dgeec. mec.pt/np4/465. Acesso em: maio 2021.

DGEEC (2020a). Educação em Números - Portugal 2019. Lisboa. Disponível em: https://www.dgeec.mec.pt/np4/96. Acesso em: maio 2021.

DGEEC (2020b). Estatísticas da Educação 2018/2019. Disponível em https://www. dgeec.mec.pt/np4/96/. Acesso em: maio 2021.

INE (2021) Disponível em: https://www.ine.pt/xportal/xmain?xpgid=ine_ main\&xpid=INE. Acesso em: junho 2021. 


\section{Legislação}

PORTUGAL, Decreto-Lei n. 80/1983, Publicação: Diário da República n. 33/1983, Série I de 1983-02-09, Ministério da Educação, Lisboa, p. 399-400, 9 de fev. 1983

PORTUGAL, Decreto-Lei n.ำ74/2006, Diário da República n.ำ60/2006, Série I-A, Ministério da Ciência, Tecnologia e Ensino Superior, Lisboa, p. 2242 - 2257, 24 março 2006.

PORTUGAL, Decreto-Lei n.ำ 139/2012, Publicação: Diário da República n.ำ 129/2012, Série I, Ministério da Educação e Ciência, Lisboa, p. 3476 - 3491, 5 de julho 2012.

PORTUGAL, Decreto-Lei n.ำ55/2018 (Despacho n. 6944-A/2018) Publicação:

Diário da República n.ำ129/2012, Série I, Ministério da Educação e Ciência, Lisboa, p. 2928 - 2943, 6 de julho de 2018.

Submetido em 07/09/2021.

Aprovado em 11/11/2021. 